\title{
A ABORDAGEM DO PLURALISMO DE PROCESSOS E DA EVO-DEVO EM LIVROS DIDÁTICOS DE BIOLOGIA EVOLUTIVA E ZOOLOGIA DE VERTEBRADOS
}

\begin{abstract}
Wellington Bittencourt-dos-Santos*
Charbel N. El-Hani**

RESUMO: Este artigo relata os resultados de uma análise de conteúdo comparativa de três livros didáticos de biologia evolutiva e três livros didáticos de zoologia de vertebrados, muito adotados nos cursos de formação superior de biologia de diversas universidades de países de línguas latinas e anglosaxônicas. Usando técnicas de análise de conteúdo, realizamos uma análise documental quali-quantitativa dos livros, com o objetivo de investigar a abordagem e recontextualização de conteúdos relativos à biologia evolutiva do desenvolvimento (evo-devo) e ao pluralismo de processos. Os nossos achados indicam que, nos livros de ambas as disciplinas, a recontextualização dos conteúdos vinculados ao pluralismo de processos ainda está em fase inicial, ainda que num estágio mais avançado nos livros de biologia evolutiva. Quanto aos conteúdos de evo-devo, a recontextualização já teve lugar de modo mais extensivo, particularmente nos livros de zoologia de vertebrados. Estes resultados mostram diferenças na construção do discurso pedagógico
\end{abstract} relacionadas com a estrutura do conhecimento acadêmico e os alvos da pesquisa nestas duas disciplinas.

Palavras-chave: Ensino de evolução. Ensino superior. Livros didáticos. Pluralismo de processos. Evo-devo.

\section{THE TREATMENT OF PROCESS PLURALISM AND EVO-DEVO IN EVOLUTIONARY BIOLOGY AND VERTEBRATE ZOOLOGY TEXTBOOKS}

ABSTRACT: This paper reports the results of a comparative content analysis of three evolutionary biology and three vertebrate zoology textbooks, widely adopted in higher education biology courses in many universities of Latin and Anglo-Saxon countries. Using techniques of content analysis, we performed a quali-quantitative documentary analysis of the textbooks, aiming at investigating the treatment and recontextualization of contents related to evolutionary developmental biology (evo-devo) and process pluralism. Our findings indicate that the recontextualization of contents associated with process pluralism is still in an initial phase in textbooks of both disciplines, even though in a more advanced stage in evolutionary biology textbooks. Regarding evo-devo contents, recontextualization has already taken place in a more extensive manner, particularly in vertebrate zoology textbooks. These results show differences in the construction of pedagogical discourse related to the structure of academic knowledge and the research targets in these disciplines.

Keywords: Evolution teaching. Higher education. Textbooks. Process pluralism. Evo-devo. 


\section{INTRODUĈ̣̃O}

A situação atual da biologia evolutiva é marcada por debates em torno do poder explicativo e do potencial heurístico da teoria sintética da evolução que têm mostrado limites importantes no que diz respeito à compreensão de uma série de fenômenos evolutivos. Esses limites têm sido destacados, em particular, pela ideia de que não somente a seleção natural, mas também diversos outros mecanismos ou fatores têm papel causal e explicativo na evolução dos seres vivos, sendo importante ressaltar, contudo, que todos esses mecanismos estão situados dentro de um quadro naturalista (EL-HANI; SEPULVEDA, 2008; EL-HANI; MEYER; SEPULVEDA, 2011), ou seja, mobilizam somente causas naturais na explicação dos fenômenos evolutivos. O pensamento evolutivo vivencia, pois, um momento intenso de desenvolvimento e reformulações, passando por novas concepções que buscam caracterizar esse novo cenário na biologia evolutiva em termos de um pluralismo de processos (EL-HANI; MEYER, 2005; KAPLAN; PIGLIUCCI , 2000). De um lado, não temos, em tal contexto histórico, uma revolução kuhniana, na medida em que não há incomensurabilidade entre as novas ideias em construção no cenário contemporâneo e a síntese moderna, construída entre as décadas de 1920e 1950; de outro, também não se tratam de meros ornamentos, na medida em que ideias centrais estão sendo acrescentadas à síntese, estendendo-a desde uma abordagem focada em mudanças de frequências gênicas em populações - como nos modelos da genética de populações - para uma abordagem causal-mecanística da origem da variação e da inovação fenotípica. É nesses termos que se pode falar, então, em uma síntese estendida ou expandida (e.g., KUTSCHERA; NIKLAS, 2004; MÜLLER, 2007; MÜLLER; PIGLIUCCI, 2010).

Por pluralismo de processos, entende-se o reconhecimento da contribuição de múltiplos mecanismos ou fatores evolutivos que atuam de modo complementar no processo evolutivo, incluindo seleção natural, deriva gênica, plasticidade fenotípica, mecanismos epigenéticos de herança, distintos modos de especiação, construção de nicho, restrições ao processo evolutivo (sejam históricas ou desenvolvimentais), evolvabilidade, simbiogênese, auto-organização, etc. Nesse cenário, é importante ter clareza de quais, exatamente, são os pontos de debate. A proposta de uma síntese estendida, como deixa clara sua própria denominação, não incorpora uma visão antiselecionista, dado que o papel da seleção natural continua sendo considerado de fundamental importância para a elucidação dos processos evolutivos, não obstante a efetiva perda de poder explicativo que a afeta, na exata medida em que o papel explicativo de outros mecanismos ou fatores passa a ser reconhecido. Dizer que se trata de uma síntese estendida significa afirmar que essa é uma teoria também darwinista, sendo aplicado o adjetivo "darwinista", como propõe Gould (2002), a teorias que mantêm um reconhecimento do papel e da importância da seleção natural no processo evolutivo. Contudo, abordar os fenômenos evolutivos dentro de uma perspectiva pluralista requer mais do que fornecer, como em uma perspectiva adaptacionista (CAPONI, 2011; EL-HANI; SEPULVEDA, 2008; 
EL-HANI; MEYER; SEPULVEDA, 2011), explicações para todas as modificações observadas na história evolutiva dos grupos de organismos apenas em termos da ação da seleção natural. Torna-se necessário compreender a possível influência de outros mecanismos ou fatores evolutivos, que podem estar atuando de modo antagonístico ou sinergístico à seleção.

Dentro da construção da síntese estendida, um campo que tem recebido grande atenção é a biologia evolutiva do desenvolvimento, em geral referida como evo-devo, que passou a ter, nas últimas décadas, um papel central na compreensão da evolução (e.g. ARTHUR, 2002, 2011; CARROLL et al., 2005; CARROLL, 2008; LAUBICHLER; MAIENSCHEIN, 2007; LOVE, 2006; MÜLLER; NEWMAN, 2003; MÜLLER, 2007; ROBERT, 2004). ${ }^{1}$ O foco, nesse caso, recai sobre organismos multicelulares nos quais a variação e inovação fenotípicas decorrem de processos de desenvolvimento e, em particular, de morfogênese, de modo que não se pode pôr de lado a relação entre desenvolvimento e evolução e, em particular, entre a variação disponível nas populações e a seleção natural, que atua sobre o repertório (sempre restrito, em maior ou menor grau) de variantes produzidas pelo desenvolvimento, a depender de vias desenvolvimentais herdadas na história de cada clado. Ao mesmo tempo em que o desenvolvimento resulta nas inovações morfológicas submetidas à ação da seleção natural, ele também restringe as possíveis modificações que podem ocorrer nas morfologias dos organismos. Ou seja, o desenvolvimento impõe limites às possibilidades de variação das características que uma população pode expressar, na medida em que não é infinitamente plástico. Os processos de geração da forma ao longo do desenvolvimento resultam, pois, em restrições desenvolvimentais, que enviesam a distribuição de variantes em uma população, uma vez que propriedades entrincheiradas dos sistemas de desenvolvimento, ou seja, que admitem menos variação, tornam certas formas de mudança mais prováveis do que outras. Para usar uma analogia proposta por Goodwin (1986), isso significa que a seleção não pode escolher qualquer "prato" no "restaurante" das formas variantes de vida, mas apenas "pratos" disponíveis no "cardápio" estabelecido pelo desenvolvimento.

Uma vez que a seleção natural atua sobre um repertório limitado de formas produzidas pelos processos desenvolvimentais, a evolução e o desenvolvimento se influenciam mutuamente, embora representem processos distintos que atuam em níveis de organização e escalas temporais diferentes: o desenvolvimento no nível do organismo individual e ao longo da vida deste, no tempo ontogenético, e de uma maneira transformacional; e a evolução ao longo das gerações das populações que constituem uma linhagem, no tempo filogenético, e de uma maneira variacional. ${ }^{2}$ Compreender adequadamente a relação entre desenvolvimento e evolução requer tanto entender suas influências mútuas como não perder de vista as diferenças entre esses dois processos. Afinal, a história do pensamento evolutivo é marcada por muitas dificuldades para a formulação de uma teoria consistente e empiricamente adequada que foram decorrentes de confusão entre desenvolvimento e evolução (e.g., BOWLER, 2003). 
Não se pode perder de vista, ainda, que o desenvolvimento, como as demais características dos indivíduos em uma população, também é alvo da seleção natural, da deriva e de outros processos, e se modifica no decorrer do processo evolutivo. Uma vez que o desenvolvimento dos indivíduos de uma espécie depende, fundamentalmente, de vias desenvolvimentais herdadas de linhagens anteriores, e a seleção tem papel importante (mas não exclusivamente determinante) na distribuição das vias que serão herdadas, a seleção influencia o desenvolvimento tanto quanto este a influencia. Os organismos recebem um legado desenvolvimental por meio da herança, não somente genética, mas também epigenética; dessa maneira, reproduz, em parte, os padrões de desenvolvimento dos seus ancestrais (JABLONKA; LAMB, 2006). Por conseguinte, é essa herança de padrões de desenvolvimento que determina os limites e as possibilidades das inovações morfológicas das futuras gerações. Consequentemente, devemos entender os estudos relativos à restrição desenvolvimental como fundamentais para a elucidação da origem e transformação das estruturas morfológicas, ao longo da história filogenética dos grupos. Essas restrições desenvolvimentais promovem um enviesamento na produção das variantes fenotípicas, dado que limitam a variabilidade em função da estrutura, do caráter, da composição e/ou da dinâmica do sistema desenvolvimental (MAYNARD SMITH et al., 1985). Contudo, elas não cumprem apenas um papel negativo na evolução, na medida em que podem também canalizar processos de mudança evolutiva, acelerando a transformação da forma orgânica nas linhagens e mesmo estabelecendo direcionalidade no processo evolutivo (GOULD, 2002).

A biologia evolutiva do desenvolvimento também desempenha outro papel relevante na reestruturação do pensamento evolutivo, na medida em que contribui para a superação do gradualismo estrito que caracterizou a síntese moderna, ao fornecer uma base causal-mecanística que nos permite explicar mudanças na velocidade das taxas evolutivas, decorrentes de uma dinâmica de profusão de inovações morfológicas que podem ser explicadas com base em alterações regulatórias no desenvolvimento. A evo-devo explica como alterações nos padrões de expressão gênica, decorrentes de mudanças nas sequências regulatórias de genes desenvolvimentais, podem conduzir a mudanças radicais na morfologia, canalizando o surgimento de novidades evolutivas (WAGNER, 2000). Nesses casos, podem ser originadas grandes mudanças na morfologia dos organismos a partir de pequenas mudanças nas sequências de DNA em regiões regulatórias, com certas estruturas morfológicas surgindo por meio de uma transformação discreta e completa, sem uma série gradual de etapas intermediárias entre uma forma e outra, estendida ao longo de muitas gerações. Essas mudanças, ditas homeóticas, contrastam com a ênfase, na teoria sintética da evolução assim como na teoria darwinista original, sobre o acúmulo lento e gradual de pequenas modificações ao longo de grandes escalas temporais, pela ação exclusiva do mecanismo de seleção natural. Hoje, é possível entender como mudanças no desenvolvimento podem rapidamente dar origem a indivíduos muito diferentes das médias morfológicas das populações às quais pertencem, por meio de mecanismos estudados pela evo-devo. Se, de um 
lado, essas mudanças morfológicas são demasiadamente rápidas para serem explicadas apenas pelo poder cumulativo da seleção natural, de outro não podemos perder de vista que elas, como quaisquer inovações morfológicas, são submetidas à peneira da seleção. Portanto, se tiveram consequências evolutivas, é porque foram preservadas em determinados regimes seletivos que favoreceram morfologias muito distanciadas da média de uma população, ou, alternativamente, em circunstâncias ambientais em que a força da seleção natural foi relaxada - por exemplo, em circunstâncias nas quais efeito fundador e deriva se tornam muito frequentes.

Diante desse quadro de mudanças conceituais na biologia evolutiva, entendemos que emerge, na atualidade, uma necessidade de compreender a evolução por meio de um conhecimento integrado de múltiplos mecanismos e fatores evolutivos em um contexto de condições históricas, desenvolvimentais e ecológicas. De uma perspectiva educacional, coloca-se a questão de como trabalhar com um conhecimento integrado e pluralista sobre o processo evolutivo na formação de biólogos, tanto aqueles que se direcionarão para a pesquisa acadêmica e a atuação técnica, quanto aqueles que serão professores de biologia. Temos investigado, assim, o conhecimento escolar de evolução, nos níveis médio e superior, tanto em termos de um diagnóstico de sua situação corrente, quanto em termos da construção de inovações pedagógicas que permitam não somente ensinar sobre ideias fundamentais da biologia evolutiva de modo efetivo, mas também introduzir, ao menos, alguns elementos dos debates contemporâneos que discutimos acima. O presente artigo está focado em um objetivo de diagnóstico e no contexto do ensino superior, dentro desse programa de pesquisa mais amplo. Trata-se de um estudo sobre se e como livros didáticos de ensino superior das áreas de biologia evolutiva e zoologia de vertebrados têm tratado de conteúdos relativos ao pluralismo de processos e à evo-devo. Estamos interessados, assim, na recontextualização pedagógica dos conhecimentos sobre evo-devo e pluralismo de processos no ensino superior de evolução, uma vez que, caso tenha ocorrido, deverá produzir um marco de referência para que essa recontextualização tenha lugar no ensino de outros campos da biologia, como no ensino de zoologia. Daí decorre nosso foco em livros didáticos de biologia evolutiva, como um possível primeiro campo de recontextualização pedagógica desses novos conhecimentos sobre evolução, e de zoologia de vertebrados, como um campo subsequente no qual tal recontextualização pode ter lugar.

O foco em livros didáticos se explica, por sua vez, pelo papel que cumprem na construção da prática pedagógica, tanto na educação básica quanto no ensino superior, influenciando de modo substancial a formação de cientistas e professores de ciências. Livros didáticos influenciam fortemente a prática da maioria dos professores e a aprendizagem dos estudantes, sendo frequentemente um dos principais determinantes do currículo em ação, dado seu papel na seleção e sequenciação de conteúdos, atividades de aprendizagem, abordagens de avaliação, etc. (BALL; FEIMAN-NEMSER, 1988; BELTRÁN et al., 2003; GARCÍA; GAYÁN, 1997). Eles são, pois, mais do que um material de leitura. São mediadores do conhecimento presente na ciência escolar e fontes estruturadoras das atividades em 
sala de aula (DIGISI; WILETT, 1995; MOODY, 2000). A relevância de investigar livros didáticos do ensino superior também decorre de sua influência sobre os livros da educação básica. Afinal, os primeiros desempenham um papel na formação dos próprios autores de livros didáticos voltados para a educação básica, tendo influência importante, pois, na constituição dos discursos sobre evolução presentes nas salas de aula de biologia e ciências nesse nível educacional.

\section{METODOLOGIA}

\subsection{Constituição do corpus de análise}

Os livros didáticos submetidos à análise foram selecionados pela representatividade de seu uso em cursos de evolução e zoologia de vertebrados de universidades situadas em países de língua latina e anglo-saxônica. O corpus de análise foi constituído por três livros didáticos de biologia evolutiva e três de zoologia de vertebrados. Para selecionar os livros, fizemos um levantamento de ementas de cursos dessas áreas por meio da ferramenta de buscas Google ${ }^{\circledR}$, utilizando, em associação com a palavra-chave "ementa", as seguintes palavras-chave: "biologia evolutiva", "teoria evolutiva", "zoologia vertebrados" e "faculdade biologia”. Os resultados da busca foram examinados na ordem fornecida pelo Google ${ }^{\circledR}$, que atende ao critério de ordenação decrescente com base no número de acessos efetivados pelos usuários da internet. As buscas foram realizadas em português, inglês e espanhol, a fim de aumentar a representatividade da amostra de obras utilizadas em programas de formação superior de biólogos em diversas universidades do mundo anglo-saxão e latino.

Nos livros de evolução, nosso foco de análise recaiu sobre o tratamento de diversos mecanismos evolutivos que são mencionados como parte de uma visão pluralista. No caso dos livros de zoologia de vertebrados, focamos nossa atenção nas narrativas evolutivas acerca da conquista do ambiente terrestre e da diversificação dos tetrápodes, que têm papel chave na evolução dos vertebrados. Isso permitiu examinar o tratamento dos mecanismos evolutivos no contexto de eventos específicos, em contraste com uma tentativa de recobrir todas as discussões sobre a evolução de diferentes grupos de vertebrados, o que dificultaria o aprofundamento da análise.

Devido ao fato de muitas mudanças no pensamento evolutivo, assim como novas interpretações e evidências sobre a conquista do ambiente terrestre pelos tetrápodes terem ocorrido na última década, foram incluídas apenas obras que continham edições nos últimos dez anos, a contar do ano em que foi feito o levantamento (2008). Afinal, tais mudanças, interpretações e evidências só poderiam estar presentes em edições mais recentes. Nossa intenção inicial era analisar 100 ementas em língua portuguesa (pelo interesse em livros usados no Brasil), 100 ementas em língua inglesa (língua mais utilizada pela comunidade científica) e 50 ementas em língua espanhola. As ementas em espanhol foram analisadas com o 
intuito de verificar se o mesmo padrão encontrado em inglês e português seria repetido em um idioma também muito utilizado pela comunidade científica, assim como na literatura de cursos de formação superior, especialmente no contexto ibero-americano. $\mathrm{O}$ mesmo padrão foi de fato encontrado nas ementas em língua espanhola, reforçando nossa confiança na seleção dos livros a serem analisados.

Ao fim do nosso esforço amostral, obtivemos valores bastante próximos das cotas pretendidas. Houve, contudo, um pequeno desequilíbrio entre o número de ementas das disciplinas de biologia evolutiva e zoologia de vertebrados. Foram obtidas, ao fim e ao cabo, 106 ementas em língua portuguesa, sendo 54 de zoologia de vertebrados e 52 de evolução; 94 ementas em língua inglesa, sendo 37 de zoologia de vertebrados e 57 de biologia evolutiva; e 50 ementas em língua espanhola, sendo 26 de zoologia de vertebrados e 24 de evolução. O total, portanto, foi de 117 ementas de zoologia de vertebrados e 133 de biologia evolutiva. Com base no número de ocorrências encontradas nessas ementas, as seguintes obras de zoologia de vertebrados foram identificadas como as três mais freqüentemente usadas: Pough et al. (2008), Hickman et al. (2007) e Hildebrand; Goslow (1998). Entre as três obras de evolução, por sua vez, temos: Ridley (2006), Futuyma (2009) e Stearns; Hoekstra (2005). Nas Tabelas 1 e 2, os resultados dos levantamentos de livros didáticos são apresentados de modo sintético, incluindo alguns outros livros mencionados em uma série de ementas. ${ }^{3}$

\subsection{Análise dos livros didáticos}

Uma vez selecionado o corpus da análise, os livros foram submetidos a uma análise de conteúdo (BARDIN, 2000), um conjunto de técnicas de análise das comunicações que utiliza procedimentos sistemáticos e objetivos de descrição do conteúdo das mensagens. Por meio da busca de indicadores, os quais podem ser qualitativos e/ou quantitativos, essa técnica de análise possibilita acessar tendências presentes, muitas vezes de modo implícito, nas mensagens contidas nos textos. Além disso, ela torna possível realizar inferências a respeito das condições de produção/recepção das mensagens encontradas nos livros analisados. Entre as técnicas de análise de conteúdo, utilizamos a análise categorial, que envolve operações de desagregação dos textos em unidades de análise, as categorias, construídas por meio de reagrupamentos analógicos.

Tabela 1: Livros didáticos de biologia evolutiva mais frequentes em ementas de cursos de nível superior localizadas por meio de busca no Google ${ }^{\circledR}$, com palavras-chave em português, inglês e espanhol.

\begin{tabular}{|c|c|c|c|c|}
\hline Biologia evolutiva & Inglês & Português & Espanhol & Total \\
\hline Futuyma (2009) & 17 & 34 & 20 & 71 \\
\hline Ridley (2006) & 16 & 15 & 15 & 46 \\
\hline Stearns; Hoekstra (2005) & 15 & 7 & 11 & 33 \\
\hline Freeman; Herron (2007) & 14 & 5 & 9 & 28 \\
\hline Dawkins (2009) & 8 & 4 & 8 & 20 \\
\hline
\end{tabular}

Revista Ensaio | Belo Horizonte | v.15 | n. 03 | p. 199-216 | set-dez | 2013 
Tabela 2: Livros didáticos de zoologia de vertebrados mais frequentes em ementas de cursos de nível superior localizadas por meio de busca no Google ${ }^{\circledR}$, com palavras-chave em português, inglês e espanhol.

\begin{tabular}{|c|c|c|c|c|}
\hline Zoologia de Vertebrados & Inglês & Português & Espanhol & Total \\
\hline Pough et al. (2008) & 12 & 45 & 5 & 62 \\
\hline Hickman et al. (2007) & 9 & 18 & 23 & 50 \\
\hline Hildebrand; Goslow (1998) & 0 & 31 & 4 & 35 \\
\hline Kardong (2008) & 2 & 2 & 0 & 4 \\
\hline
\end{tabular}

Uma análise de conteúdo inclui três etapas: (I) pré-análise; (II) análise; (III) categorização. Durante a pré-análise, foi realizada uma "leitura flutuante" do material, ou seja, uma primeira leitura, menos sistemática, que permitiu uma familiarização inicial com os livros e, ao mesmo tempo, o reconhecimento e a identificação das unidades de registro, ou seja, dos trechos dos livros que veiculavam conteúdos relacionados a fatores ou mecanismos evolutivos, relevantes para a análise da abordagem do pluralismo de processos, e/ou a conteúdos pertinentes à evo-devo. Os reagrupamentos feitos na técnica de análise categorial foram obtidos pela busca de características compartilhadas pelas unidades de registro, o que pode ser feito mediante critérios semânticos (i.e., busca da presença de um mesmo significado em um determinado contexto) ou sintáticos (como a presença compartilhada de signos linguísticos precisos). Em nosso trabalho, utilizamos um recorte de ordem sintática, com as unidades de registro sendo localizadas a partir de palavras-chave previamente definidas, que indicavam fatores ou mecanismos evolutivos considerados de acordo com uma visão pluralista da evolução, ou conteúdos da evo-devo.

Foram utilizadas como indicadores de busca as seguintes palavras-chaves, as quais, quando encontradas nos textos, permitiam localizar as unidades de registro: "seleção" e "seleção natural", para identificação do mecanismo de seleção natural; "evo-devo", "genes hox" e "desenvolvimento", para a biologia evolutiva do desenvolvimento; "deriva" e "deriva gênica", para deriva gênica; "mecanismos macroevolutivos" e "macroevolução", para os mecanismos macroevolutivos; "especiação", para identificar distintos modos de especiação; "auto-organização", "simbiogênese", "restrição" e "construção de nicho", para os respectivos fatores evolutivos. Não foram obtidas, portanto, categorias de modo indutivo a partir das unidades de registro. As categorias foram previamente estabelecidas como meio de verificar até que ponto contribuições recentes relativas à evo-devo e ao pluralismo de processos eram abordadas, em primeiro lugar, nos livros didáticos de biologia evolutiva, nos quais assumimos ser mais provável sua recontextualização didática, e, em segundo lugar, nos livros didáticos de zoologia de vertebrados. A lista de mecanismos ou fatores evolutivos que utilizamos foi elaborada com base na literatura sobre evolução utilizada na fundamentação teórica do estudo, tendo sido validada e complementada pela consulta a um pesquisador especializado na área de biologia evolutiva, o professor Diogo Meyer (IB-USP). 
$\mathrm{Na}$ fase de análise, os seis livros foram examinados integralmente, localizando as unidades de registro e transcrevendo-se em uma tabela tanto essas unidades quanto as unidades de contexto que correspondiam a trechos mais amplos do texto nos quais estavam contidas as unidades de registro. A partir das unidades de contexto foi possível analisar de modo mais preciso o significado atribuído ao termo ou conceito de interesse utilizado em cada unidade de registro.

A quantificação das unidades de registro enquadradas em cada categoria foi utilizada para avaliar a atenção e a ênfase concedida pelos livros ao pluralismo de processos e à evo-devo. Embora tenhamos trabalhado com dados quantitativos, os valores de ocorrência das categorias serviram como orientação para uma análise de caráter qualitativo, a qual utilizou a regularidade com que as unidades de registro apareceram como um parâmetro de interpretação da significância concedida aos referidos conteúdos. Por essa razão, caracterizamos esse estudo como quali-quantitativo.

\section{RESULTADOS E DISCUSSÃO}

Como pode ser visto na tabela 3 , os livros de biologia evolutiva analisados já trazem, em suas explicações, uma abordagem de parte dos fatores ou mecanismos considerados segundo uma visão pluralista do processo evolutivo. As contribuições da evo-devo, os mecanismos de especiação e a deriva gênica recebem atenção nos livros, com algum destaque - ainda que bastante limitado para os mecanismos macroevolutivos e às restrições. $\mathrm{O}$ efeito fundador merece consideração ainda mais limitada, mas não devemos perder de vista suas relações íntimas com a deriva.

Tabela 3: Números de ocorrências e frequências total e relativa de cada uma das categorias presentes nos livros didáticos de biologia evolutiva e zoologia de vertebrados analisados. Os dados completos, incluindo todas as unidades de registro e de contexto, podem ser solicitados aos autores do artigo. 


\begin{tabular}{|c|c|c|c|c|c|c|c|c|}
\hline \multirow{2}{*}{ Categorias } & \multirow{2}{*}{\multicolumn{2}{|c|}{ Livros }} & \multicolumn{3}{|c|}{ Zoologia } & \multicolumn{3}{|c|}{ Zoologia de Vertebrados } \\
\hline & & & Futuyma & Ridley & Stearns & Pough & Hickman & Hildebrand \\
\hline \multirow{3}{*}{$\begin{array}{l}\text { Seleção } \\
\text { Natural }\end{array}$} & $\begin{array}{c}\mathrm{N}^{0} \text { de } \\
\text { Ocorrências }\end{array}$ & Seleção* & 722 & 987 & 514 & 31 & 110 & 25 \\
\hline & \multicolumn{2}{|c|}{ Frequência total: } & 722 & 987 & 514 & 31 & 110 & 25 \\
\hline & \multicolumn{2}{|c|}{ Frequência relativa (\%): } & $56,8 \%$ & $51,4 \%$ & $46,6 \%$ & $47,7 \%$ & $40,9 \%$ & $34,7 \%$ \\
\hline \multirow{5}{*}{ Evo-devo } & \multirow{3}{*}{$\begin{array}{c}\mathrm{N}^{0} \text { de } \\
\text { Ocorrências }\end{array}$} & Desenvolvimento* & 162 & 182 & 239 & 14 & 73 & 22 \\
\hline & & Gene Hox & 28 & 55 & 29 & 15 & - & 21 \\
\hline & & Evo-devo & 1 & 19 & - & 5 & - & - \\
\hline & \multicolumn{2}{|c|}{ Frequência total: } & 191 & 256 & 268 & 34 & 73 & 43 \\
\hline & \multicolumn{2}{|c|}{ Frequência relativa (\%): } & $15 \%$ & $13,3 \%$ & $24,3 \%$ & $52,3 \%$ & $27,1 \%$ & $59,7 \%$ \\
\hline \multirow{3}{*}{ Especiação } & \multicolumn{2}{|c|}{$N^{0}$ de Ocorrências } & 172 & 315 & 134 & - & 49 & - \\
\hline & \multicolumn{2}{|c|}{ Frequência total: } & 172 & 315 & 134 & - & 49 & - \\
\hline & \multicolumn{2}{|c|}{ Frequência relativa (\%): } & $13,5 \%$ & $16,4 \%$ & $12,1 \%$ & $0 \%$ & $18,2 \%$ & $0 \%$ \\
\hline \multirow{4}{*}{ Deriva Gênica } & \multirow{2}{*}{$\begin{array}{c}\mathrm{N}^{0} \text { de } \\
\text { Ocorrências }\end{array}$} & Deriva Gênica & - & 47 & 53 & - & 18 & - \\
\hline & & Deriva & 133 & 214 & 61 & - & - & - \\
\hline & \multicolumn{2}{|c|}{ Frequência total: } & 133 & 263 & 114 & - & 18 & - \\
\hline & \multicolumn{2}{|c|}{ Frequência relativa (\%): } & $10,4 \%$ & $13,7 \%$ & $10,3 \%$ & $0 \%$ & $6,7 \%$ & $0 \%$ \\
\hline \multirow{4}{*}{$\begin{array}{c}\text { Mecanismos } \\
\text { Macro- } \\
\text { evolutivos }\end{array}$} & \multirow{2}{*}{$\begin{array}{c}N^{0} \text { de } \\
\text { Ocorrências }\end{array}$} & $\begin{array}{c}\text { Mecanismos } \\
\text { Macroevolutivos }\end{array}$ & - & - & - & - & - & - \\
\hline & & Macroevolução & 15 & 50 & 38 & - & 11 & - \\
\hline & \multicolumn{2}{|c|}{ Frequência total: } & 14 & 50 & 38 & - & 11 & - \\
\hline & \multicolumn{2}{|c|}{ Frequência relativa (\%): } & $1,1 \%$ & $2,6 \%$ & $3,4 \%$ & $0 \%$ & $4,1 \%$ & $0 \%$ \\
\hline \multirow{3}{*}{ Restrições } & \multicolumn{2}{|c|}{$N^{0}$ de Ocorrências } & 33 & 43 & 29 & - & 8 & 4 \\
\hline & \multicolumn{2}{|c|}{ Frequência total: } & 33 & 43 & 29 & - & 8 & 4 \\
\hline & \multicolumn{2}{|c|}{ Frequência relativa (\%): } & $2,6 \%$ & $2,2 \%$ & $2,6 \%$ & $0 \%$ & $3 \%$ & $5,6 \%$ \\
\hline \multirow{3}{*}{$\begin{array}{c}\text { Efeito } \\
\text { Fundador }\end{array}$} & \multicolumn{2}{|c|}{$N^{0}$ de Ocorrências } & 7 & 5 & 6 & - & - & - \\
\hline & \multicolumn{2}{|c|}{ Frequência total: } & 7 & 5 & 6 & - & - & - \\
\hline & Frequêr & ia relativa $(\%)$ : & $0,6 \%$ & $0,4 \%$ & $0,5 \%$ & $0 \%$ & $0 \%$ & $0 \%$ \\
\hline Construção & $N^{0} d \epsilon$ & corrências & - & - & - & - & - & - \\
\hline Auto- & Freq & ência total: & - & - & - & - & - & - \\
\hline Simbiogênese & Frequêr & ia relativa (\%): & $0 \%$ & $0 \%$ & $0 \%$ & $0 \%$ & $0 \%$ & $0 \%$ \\
\hline
\end{tabular}

*Só foram consideradas as ocorrências dos termos 'desenvolvimento' e 'seleção' que tinham conexão com conteúdos evolutivos. 
O trecho a seguir exemplifica a abordagem da evo-devo em um dos livros de biologia evolutiva analisados:

O campo da biologia evolutiva do desenvolvimento, ou EDB (frequentemente chamado de "evo-devo"), procura compreender os mecanismos pelos quais o desenvolvimento evoluiu, tanto em termos de processos desenvolvimentais (por exemplo, quais interações celulares e tissulares novas são responsáveis por novas morfologias em certos taxa) quanto em termos de processos evolutivos (por exemplo, que pressões seletivas promoveram a evolução dessas novas morfologias) (FUTUYMA, 2009, p. 474). ${ }^{4}$

Nesta passagem de outro livro didático, mecanismos de especiação são discutidos:

Quais os fatores determinam os padrões de especiação e radiação? A questão tem sido estudada de várias formas e [...] vamos nos concentrar em duas ideias: uma na qual os atributos dos organismos podem influenciar as probabilidades de sobrevivência e especiação de um táxon, e outro na qual fatores ecológicos externos podem mostrar tal influência (RIDLEY, 2004, p. 658). ${ }^{5}$

Em outro livro didático, podemos citar como exemplo do tratamento da deriva gênica o seguinte excerto:

Uma vez que as populações ancestrais eram moderadamente grandes, a deriva foi provavelmente causada pela variação no sucesso reprodutivo feminino, e não pelos efeitos fundador e de bottleneck, genético (STEARNS; HOEKSTRA, 2005, p. 337). ${ }^{6}$

O seguinte trecho, por sua vez, aborda efeito fundador, macroevolução, deriva gênica e restrições, no contexto da teoria do equilíbrio pontuado, proposta por Gould e Eldredge:

Eldredge e Gould aplicaram o modelo de especiação por efeito fundador de Mayr à mudança macroevolutiva, propondo que a maioria das características morfológicas não pode evoluir (por causa de restrições genéticas internas) exceto quando a deriva gênica inicia um deslocamento para um novo equilíbrio adaptativo (FUTUYMA, 2009, p. 502). ${ }^{7}$

Outros mecanismos ou fatores, como a simbiogênese, a auto-organização e a construção de nicho, não são levados em conta. Podemos concluir, assim, que os livros de biologia evolutiva já trazem uma perspectiva pluralista, inclusive levando em conta as contribuições da evo-devo, mas a maior atenção se dirige, de qualquer modo, à seleção natural, que apareceu com alta frequência relativa nos livros, quando comparada às frequências relativas das demais categorias. Este é um exemplo de ocorrência do conceito de seleção natural:

"Embora seja meramente um enunciado sobre taxas de reprodução e mortalidade, a teoria da seleção natural é talvez a mais importante ideia na biologia (FUTUYMA, 2009, p. 247)." 
Já está em andamento, nos livros de biologia evolutiva analisados, uma recontextualização pedagógica do pluralismo de processos, que tem marcado cada vez mais o conhecimento acadêmico sobre evolução. Todavia, essa recontextualização ainda está se iniciando, como mostra a grande ênfase dada à seleção natural em relação aos outros mecanismos e o fato de que os demais mecanismos evolutivos ainda não são explorados de modo mais aprofundado. Isso fica claro quando percebemos que boa parte dos conteúdos relativos a mecanismos evolutivos que não sejam a seleção natural aparece em apêndices, notas de rodapé, leituras complementares, ou em capítulos específicos, nos quais são abordados de maneira fragmentada, sem a devida integração aos demais conteúdos abordados pelo livro.

Os conhecimentos científicos naturalmente percorrem uma trajetória de reconstrução até se fazerem presentes no conhecimento científico escolar. É esperado, assim, que se passe algum tempo até que determinados desenvolvimentos estejam representados na ciência escolar. Além disso, essa recontextualização depende de outros fatores, como a real contribuição que os novos conhecimentos trazem para o ensino e a aprendizagem em diferentes níveis educacionais. Estamos assumindo, pois, que os desenvolvimentos recentes que conduziram a biologia evolutiva rumo a uma visão mais pluralista são suficientemente importantes para a formação dos biólogos, a ponto de deverem estar presentes nos livros didáticos. $\mathrm{O}$ que podemos perceber nos livros de biologia evolutiva é que o tempo transcorrido já foi suficiente para que boa parte dos mecanismos considerados de acordo com uma visão pluralista do processo evolutivo esteja neles representada, com exceção de alguns mecanismos e com manutenção de uma predominância da seleção natural (o que pode ser entendido como reflexo da importância desse mecanismo, mas também indica uma sobrevivência da ênfase sobre esse mecanismo na teoria sintética). Ainda resta por ser feita, contudo, uma exploração mais aprofundada de tais mecanismos, o que naturalmente colocará em nova perspectiva o tratamento dado à seleção.

Na Tabela 3, podemos ver que, com exceção da seleção natural, os demais mecanismos ou fatores evolutivos estão quase sempre ausentes dos livros didáticos de zoologia de vertebrados. Contudo, houve grande frequência de ocorrências relacionadas à evo-devo. Segue um exemplo retirado de um dos livros didáticos analisados:

Os genes Hox não codificam características específicas diretamente: eles regulam a expressão e a hierarquia de outros genes que controlam o formato do corpo, especialmente o processo do desenvolvimento ao longo do eixo da região cranial para a região caudal (POUGH et al., 2006, p. 22).

Podemos concluir, assim, que os livros de zoologia de vertebrados não apresentam uma abordagem pluralista do processo evolutivo, com exceção da atenção dada à relação entre evolução e desenvolvimento, nos marcos da evo-devo. A recontextualização do pluralismo de processos parece ser ainda incipiente nesse campo. 
De um modo geral, foi possível notar um maior avanço da recontextualização dos conteúdos relativos à evo-devo em relação a outros elementos de uma síntese estendida. Tal afirmação é válida tanto para os livros de biologia evolutiva como para os de zoologia de vertebrados. Esse achado traz à tona a preocupação de que a mudança teórica em andamento na biologia evolutiva esteja sendo tomada, no processo de recontextualização pedagógica, como sendo restrita à evo-devo, o que não se mostra correto.

Em todos os seis livros, é possível identificar o tratamento de assuntos concernentes à biologia evolutiva do desenvolvimento, sendo que, entre todas as categorias consideradas na análise dos livros didáticos de biologia evolutiva, esta teve a segunda maior frequência relativa, superada apenas pela categoria seleção natural. Entre os livros de zoologia de vertebrados, os mesmos resultados foram encontrados no livro de Hickman et al. (2007), que se diferenciou por apresentar uma visão mais pluralista. Nos outros dois livros, Pough et al. (2008) e Hildebrand e Goslow (1998), os conteúdos relativos à evo-devo foram os mais frequentes entre todas as categorias encontradas, superando, inclusive, a seleção natural. Isso mostra a atenção dada à compreensão da evolução do desenvolvimento e de suas consequências para a evolução dos grupos de animais na zoologia de vertebrados. Esse achado pode ser entendido pelo fato de que a pesquisa em evo-devo tem dado contribuições fundamentais e de grande alcance nos estudos sobre vertebrados. Em termos mais gerais, a evo-devo tem cumprido papel central nos avanços dos últimos trinta anos sobre a compreensão dos planos de organização dos corpos de animais (CARROLL et al., 2005; CARROLL, 2008; DAVIDSON; ERWIN, 2006; KURATANI, 2009; MINELLI, 2003; SWALLA, 2006; ARTHUR, 2011). Não espanta, assim, a atenção dada a ela nos livros de zoologia analisados.

No livro de Hickman et al. (2007), temos um padrão diferenciado em relação aos outros dois livros de zoologia de vertebrados, com a presença de uma visão mais pluralista, contemplando, além da evo-devo, modos de especiação, deriva gênica, mecanismos macroevolutivos e restrições. Seguem exemplos do tratamento dos dois últimos fatores citados:

A macroevolução se refere à evolução em grande escala, abrangendo as origens de novas estruturas e novos planos corporais organísmicos, tendências evolutivas, radiação adaptativa, relações filogenéticas de espécies e extinção em massa (HICKMAN et al., 2007, p. 124). ${ }^{9}$

Em cada estágio do desenvolvimento, novas estruturas surgem da interação de rudimentos menos comprometidos [com determinado futuro celular]. Cada interação é cada vez mais restritiva, e a decisão tomada em cada etapa na hierarquia limita ainda mais o destino desenvolvimental (HICKMAN et al., 2007, p. 157). ${ }^{10}$

O seguinte trecho exemplifica a abordagem da evo-devo nesse livro:

"Durante as duas últimas décadas a combinação da genética com modernas técnicas da biologia molecular e celular produziu uma avalanche de informações que resolveu muitas 
perguntas. As relações causais entre o desenvolvimento e a evolução se tornaram o grande foco de investigação" (HICKMAN et al., 2007, 157p). ${ }^{11}$

Ainda que a frequência de ocorrências que tratam de evo-devo tenha sido menor nesse livro do que nos de Pough et al. (2008) e Hildebrand e Goslow (1998), o destaque dado por Hickman e colaboradores a esse campo fica claro na presença de um capítulo exclusivamente direcionado ao tratamento das questões desenvolvimentais, intitulado Principles of development, que apresenta um enfoque de caráter propriamente evolutivo.

A diversidade de mecanismos encontrada nos livros foi um dos parâmetros importantes em nossa análise. Para tanto, comparamos, em cada livro, os números de categorias sem qualquer ocorrência com o número de categorias encontradas. Desse modo, foi possível avaliar em que medida os livros analisados contemplavam a pluralidade de processos que têm sido invocados na explicação do processo evolutivo. Mesmo em um livro de zoologia de vertebrados mais pluralista, como o de Hickman e colaboradores, não houve qualquer ocorrência em quatro categorias: auto-organização, simbiogênese, efeito fundador e construção de nicho. Nos outros dois livros desse campo, sete das nove categorias não foram encontradas. No caso dos livros de biologia evolutiva, não foram observadas quaisquer ocorrências de três categorias, sendo as mesmas nos três livros: auto-organização, construção de nicho e simbiogênese. De modo geral, esses três fatores não foram considerados em qualquer dos seis livros analisados.

Entre os fatores que não estão, ainda, presentes nos livros, temos duas situações que nos parecem distintas: de um lado, é mais provável que mecanismos como a construção de nicho venham a ser recontextualizados em futuro próximo, dado seu maior impacto na comunidade científica, como mostra a influência exercida na última década por um livro que destaca a construção de nicho como importante mecanismo evolutivo, Niche construction: the neglected process in evolution, de Odling-Smee, Laland e Feldman (2003). Em artigos das áreas de evolução e ecologia, a construção de nicho também tem merecido significativa atenção (e.g., HUI; YUE, 2005; WRIGHT et al., 2004). De outro lado, fatores como a auto-organização e a simbiogênese já não têm recebido tanta atenção da comunidade científica, podendo não ser recontextualizados, por essa razão, para o conhecimento escolar de biologia evolutiva, nem mesmo na educação superior.

\section{CONCLUSÕES}

Os resultados do presente estudo mostram que livros didáticos de biologia evolutiva atualmente em uso incluem, em suas explicações evolutivas, parte dos fatores e mecanismos considerados em visões pluralistas do processo evolutivo nas duas últimas décadas, principalmente contribuições da evo-devo, mecanismos de especiação e deriva gênica e, com menor proeminência, mecanismos macroevolutivos e restrições. Portanto, uma recontextualização pedagógica do pluralismo 
de processos já vem ocorrendo no conhecimento escolar de biologia evolutiva, no nível superior de ensino. Trata-se, contudo, de uma recontextualização ainda inicial, mantendo-se grande ênfase sobre a seleção natural em relação aos outros mecanismos, que não são abordados de modo aprofundado.

Nos livros didáticos de zoologia de vertebrados, por sua vez, seleção natural e contribuições da evo-devo são tratadas com destaque, enquanto os demais fatores evolutivos estão quase sempre ausentes. Portanto, esses livros não apresentam uma abordagem pluralista do processo evolutivo, com exceção da atenção dada à relação entre evolução e desenvolvimento. Em termos gerais, podemos perceber, em ambos os campos, um maior avanço da recontextualização dos conteúdos relativos à evo-devo em relação a outros fatores incluídos em uma visão pluralista da evolução.

À medida que a recontextualização de uma visão pluralista se aprofunde nos livros didáticos de biologia evolutiva, tendo, assim, maior influência sobre a formação de biólogos, é possível que essa visão se dissemine de modo mais amplo por diversos campos das ciências biológicas, incluindo a zoologia de vertebrados. Visando contribuir para essa incorporação do pluralismo de processos no conhecimento escolar de biologia do ensino superior, temos investigado inovações educacionais que tratam dessa visão no contexto real de salas de aula de zoologia, no curso de ciências biológicas da UFBA. O presente artigo relata os resultados de nossos primeiros passos nessa direção, que consistiram em um estudo sobre se e como livros didáticos de ensino superior das áreas de biologia evolutiva e zoologia de vertebrados tratam conteúdos relativos ao pluralismo de processos e à evo-devo.

\section{NOTAS}

${ }^{1}$ É importante, contudo, não reduzir a síntese estendida à evo-devo. Há muito mais em debate e em desenvolvimento na construção dessa nova síntese do que as relações entre evolução e desenvolvimento.

${ }^{2}$ A distinção entre explicações ou processos transformacionais e variacionais foi originalmente feita por Lewontin (LEVINS; LEWONTIN, 1985; LEWONTIN, 2000; para discussões sobre esta distinção, ver SOBER, 1993; CAPONI, 2005). Em um processo ou explicação transformacional, a evolução de um sistema ocorre por causa de mudanças combinadas e simultâneas de todos os seus componentes. No desenvolvimento, por exemplo, as mudanças sofridas pelos organismos decorrem de transformações que ocorrem em todos os seus componentes, por exemplo, tecidos e células. Em um processo ou explicação variacional, como proposto na teoria darwinista da evolução, as mudanças de um sistema decorrem de mudanças nas proporções de seus componentes, e não da transformação de cada constituinte individual. É nesses termos que entendemos a evolução, como um processo populacional.

${ }^{3}$ As tabelas completas, incluindo todos os livros encontrados na busca, podem ser solicitadas aos autores do artigo.

${ }^{4}$ As traduções foram feitas pelos autores do artigo. No original: "The field of evolutionary developmental biology, or EDB (often called “evo-devo"), seeks to understand the mechanisms

Revista Ensaio | Be10 Horizonte | v.15 | n. 03 | p. 199-216 | set-dez | 2013 
by which development has evolved, both in terms of developmental processes (for example, what novel cell or tissue interactions are responsible for novel morphologies in certain taxa) and in terms of evolutionary processes (for example, what selection pressures promoted the evolution of these novel morphologies)".

${ }^{5}$ No original: "What factors determine the patterns of speciation and radiation? The question has been studied in various ways and in this and the next section we shall concentrate on two ideas: one in which the attributes of the organisms may influence a taxon's probabilities of survival and speciation, and the other in which external ecological factors may show such an influence".

${ }^{6}$ No original: "Since the ancestral populations were moderately large, the drift was probably caused by variation in female reproductive success rather than by founder effects and genetic bottlenecks".

${ }^{7}$ No original: "Eldredge and Gould applied Mayr's model of founder effect speciation to macroevolutionary change, proposing that most morphological characters cannot evolve (because of internal genetic constraints) except when genetic drift initiates a shift to a new adaptive equilibrium".

${ }^{8}$ No original: "Although it is merely a statement about rates of reproduction and mortality, the theory of natural selection is perhaps the most important idea in biology".

${ }^{9}$ No original: "Macroevolution refers to evolution on a grand scale, encompassing the origins of new organismal structures and designs, evolutionary trends, adaptive radiation, phylogenetic relationships of species, and mass extinction".

${ }^{10}$ No original: "At each stage of development new structures arise from the interaction of less committed rudiments. Each interaction is increasingly restrictive, and the decision made at each stage in the hierarchy further limits developmental fate".

${ }^{11}$ No original: "During the last two decades the combination of genetics with modern techniques of cellular and molecular biology produced an avalanche of information that solved many questions. Causal relationships between development and evolution have also become the focus of research".

\section{AGRADECIMENTOS}

Charbel N. El-Hani agradece ao CNPq por bolsa de produtividade em pesquisa nível 1-C (n. 301259/2010-0) e à Fapesb e ao CNPq por financiamentos de projetos de pesquisa. Wellington Bittencourt dos Santos agradece à Fapesb pelo financiamento do projeto de pesquisa que derivou o presente artigo.

\section{REFERÊNCIAS}

ARTHUR, W. The emerging conceptual framework of evolutionary developmental biology. Nature, v. 415 , p. $757-764,2002$.

ARTHUR, W. Evolution: A developmental approach, Oxford: Wiley-Blackwell, 2011.

BALL, D. L.; FEIMAN-NEMSER, S. Using textbooks and teachers' guides: A dilemma for beginning teachers and teacher educators. Curriculum Inquiry, Malden, v. 18, n. 4, p. 401-423, 1988.

BARDIN, L. Análise de conteúdo. Lisboa: Edições 70, 2000. 
BELTRÁN, I. B.; RAMALHO, B. L.; SILVA, I. P.; CAMPOS, A. N. A seleção dos livros didáticos: Um saber necessário ao professor. O caso do ensino de Ciências. Revista Iberoamericana de Educación, São Carlos, 25/04/2003, disponível em: <http://www.rieoei.org/did_mat1.htm> . Acesso em 17 maio 2013.

BOWLER, P. J. Evolution: The history of an idea (3a ed). Berkeley, CA: University of California Press, 2003

CAPONI, G. O darwinismo e seu outro: A teoria transformacional da evolução. Scientiae Studia, São Paulo, v. 3, p.233-242, 2005.

CAPONI, G. La segunda agenda darwiniana: contribución preliminar a una historia del programa adaptacionista. Cidade do México: Centro de Estudios Filosóficos y Sociales Vicente Lombardo Toledano, 2011.

CARROLL, S.B. Evo-devo and an expanding evolutionary synthesis: A genetic theory of morphological evolution. Cell, v. 134, p. 25-36, 2008.

CARROLL, S. B.; GRENIER, J. K.; WEATHERBEE, S. D. From DNA to diversity: molecular genetics and the evolution of animal design. Oxford: Blackwell, 2005.

DAVIDSON, E. H.; ERWIN, D. H. Gene regulatory networks and the evolution of animal body plans. Science, São Paulo, v. 311, p. 796-800, 2006.

DAWKINS, R. The greatest show on Earth: the evidence for evolution. New York, NY: Free Press, 2009.

DIGISI, L. L.; WILETT, J.B. What high school biology teachers say about their textbook use: a descriptive study. Journal of Research in Science Teaching, v. 32, n. 2, p. 123-142, 1995.

FREEMAN, S.; HERRON, J. C. Evolutionary analysis (4th Ed.). San Francisco, CA: Benjamin Cummings, 2007.

FUTUYMA, D. J. Evolution (2 $2^{\text {nd }}$ Ed.). Sunderland, MA: Sinauer, 2009.

GAYÁN, E.; GARCÍA, P. E. Como escoger un libro de texto? Desarrollo de un instrumento para evaluar los libros de texto de ciencias experimentales. Enseñanza de las Ciencias, Vigo, Número Extra, V Congresso, p. 249-250, 1997.

GOODWIN, B. É a biologia uma ciência histórica. In: ROSE, S.; APPIGNANESI, L. (Eds.)., Para uma nova ciência. Lisboa, Gradiva, 1986, p. 65-81.

GOULD, S. J. The structure of evolutionary theory. Cambridge, MA: The Harvard University Press, 2002.

HICKMAN, C., JR., ROBERTS, L., KEEN, S., LARSON, A., I'ANSON, H., EISENHOUR, D. Integrated principles of zoology (14 ${ }^{\text {th }}$ Ed.), Boston, NJ: McGraw-Hill, 2007.

HILDEBRAND, M.; GOSLOW, G. Analysis of vertebrate structure (5a ${ }^{a}$ Ed). New York, NY: John Wiley \& Sons. 1998.

HUI, C.; YUE, D. Niche construction and polymorphism maintenance in metapopulations. Ecological Research, v. 20, p. 115-119, 2005.

JABLONKA, E.; LAMB, M. J. Evolution in four dimensions: genetic, epigenetic, behavioral, and symbolic Variation in the history of life. Cambridge, MA: The MIT Press, 2006.

KARDONG, K.V. Vertebrates: comparative anatomy, function, evolution (5th ed.). Boston, NJ: McGraw-Hill, 2008.

KURATANI, S. Modularity, comparative embryology and evo-devo: developmental dissection of evolving body plans. Developmental Biology, v. 332, p. 61-69, 2009.

KUTSCHERA, U.; NIKLAS, K. J. The modern theory of biological evolution: an expanded synthesis. Naturwissenschaften, v. 91, p. 255-276, 2004.

LAUBICHLER, M.; MAIENSCHEIN, J. (Eds.) From embryology to evo-devo: a history of developmental evolution. Cambridge, MA: The MIT Press, 2007.

LEVINS, R.; LEWONTIN, R. The dialectical biologist. Cambridge-MA: Harvard University Press, 1985.

LEWONTIN, R. The organism as the subject and object of evolution. Scientia, São Paulo, v. 118, p. 63-82, 1983.

LOVE, A. C. Evolutionary morphology and EvoDevo: hierarchy and novelty. Theory in Biosciences, v. 124, p. 317-333, 2006.

MAYNARD SMITH, J., BURIAN, R., KAUFFMAN, S., ALBERCH, P., CAMPBELL, J., GOODWIN, B., LANDE, R., RAUP, D.; WOLPERT, L. Developmental constraints and evolution: a perspective from the Mountain Lake Conference on Development and Evolution. 
The Quarterly Review of Biology, v. 60, n. 3, p. 265-287.

MEYER, D.; EL-HANI, C. N. Evolução: o sentido da biologia. São Paulo: UNESP, 2005.

MINELLI, A. The development of animal form: ontogeny, morphology, and evolution. Cambridge: Cambridge University Press, 2003.

MOODY, D.E. The paradox of the textbook. In: FISHER, K.M.; WANDERSEE, J.H.; MOODY, D. E. (Eds.), Mapping biology knowledge. Dordrecht, Netherlands: Kluwer Academic Publishers, 2000, p. 167-184.

MÜLLER, G. Evo-devo: Extending the evolutionary synthesis. Nature Reviews Genetics, v. 8, p. $943-$ 949, 2007.

MÜLLER, G.; NEWMAN, S. A. (Eds.). Origination of organismal form. Cambridge, MA: The MIT Press, 2003.

ODLING-SMEE, F. J., LALAND, K. N; FELDMAN, M.W. Niche construction: The neglected process in evolution. Princeton, NJ: Princeton University Press, 2003.

PIGLIUCCI, M.; KAPLAN, J. The fall and rise of Dr. Pangloss: Adaptationism and the Spandrels paper 20 years later. Trends in Ecology and Evolution, v. 15, n. 2, p. 66-70, 2000.

PIGLIUCCI, M.; MÜLLER, G. (Eds.) Evolution: the extended synthesis. Cambridge, MA: The MIT Press, 2010.

POUGH, F.H.; JANIS, C.M.; HEISER, J.B. A Vida dos Vertebrados. (4ª ed.). São Paulo, Atheneu Editora São Paulo, 2006.

RIDLEY, M. Evolução (3ª Ed.). Porto Alegre: Artmed, 2006.

ROBERT, J. S. Embryology, epigenesis, and evolution: taking development seriously.

Cambridge: Cambridge University Press, 2004.

SEPULVEDA, C.; EL-HANI, C. N. Adaptacionismo versus exaptacionismo: O que este debate tem a dizer ao ensino de evolução? Ciência e Ambiente, Santa Maria,v. 36, p. 93-124, 2008.

SEPUlVEDA, C., MEYER, D.; EL-HANI, C. N. Adaptacionismo. In: ABRANTES, P. (Org.). Filosofia da Biologia, Porto Alegre: ARTMED, 2011, p.162-192.

SOBER, E. The nature of selection: evolutionary theory in philosophical focus. Chicago, Il.: The University of Chicago Press, 1993.

STEARNS, S.; HOEKSTRA, R. Evolution: an introduction (2nd Ed.). New York, NY: Oxford University Press, 2005.

SWALLA, B. J. Building divergent body plans with similar genetic pathways. Heredity, v. 97, p. 235243, 2006.

WAGNER, G. What is the promise of developmental evolution? Part I: Why is developmental biology necessary to explain evolutionary innovations. Journal of Experimental Zoology, v. 288, p. 95-98, 2000.

WRIGHT, J. P., GURNEY, W. S C.; JONES, C. G. Patch dynamics in a landscape modified by ecosystem engineers. Oikos, v. 105, p.336-348, 2004. 